\title{
A FORMAÇÃO INICIAL DOS PROFESSORES DE HISTÓRIA DA UNIVERSIDADE DO ESTADO DO RIO GRANDE DO NORTE (UERN) A PARTIR DO CURRÍCULO: TRAÇOS DE UMA AUSÊNCIA ACERCA DA TEMÁTICA 'MULHERES'
}

\author{
Paulo Augusto Tamanini ${ }^{1}$ \\ Francisco Vieira da Silva ${ }^{2}$ \\ Gislânia Dias Soares ${ }^{3}$
}

\section{RESUMO}

O presente artigo tem por finalidade analisar a formação inicial dos professores de História da Universidade do Estado do Rio Grande do Norte - UERN, construída a partir do currículo oficial. Nesse ínterim, discutimos, de modo específico, o currículo do curso de História e sua relação com o ensino, a partir da temática 'mulheres'. Trata-se de uma pesquisa bibliográfica, cotejando os estudos de Bittencourt (2011), Fonseca (2003), Nóvoa (2005) e Pinsky (2009), seguida de uma análise documental da estrutura curricular 2019.1 do referido curso.

\footnotetext{
${ }^{1}$ Pós-Doutor em História pela Universidade Federal do Paraná (UFPR). Doutor em História pela Universidade Federal de Santa Catarina (UFSC). Professor do Programa de PósGraduação em Ensino - POSENSINO (UERN/UFERSA/IFRN). Coordenador do Grupo de Pesquisa Imagem e Ensino: percepções, métodos e fontes (CNPq/UFERSA). ORCID: http://orcid.org/0000-0001-6963-2952 E-mail: professor@tamanini.com.br

2 Doutor em Linguística pela Universidade Federal da Paraíba (UFPB). Professor da Universidade Federal Rural do Semi-Árido (UFERSA) e do Programa de Pós-Graduação em Letras (PPGL) da Universidade do Estado do Rio Grande do Norte (UERN) e do Programa de Pós-Graduação em Ensino (POSENSINO), da associação entre a Universidade do Estado do Rio Grande do Norte (UERN), a Universidade Federal Rural do Semi-Árido (UFERSA) e o Instituto Federal de Educação, Ciência e Tecnologia do Rio Grande do Norte (IFRN). ORCID: http://orcid.org/0000-0003-4922-8826. Email: francisco.vieiras@ufersa.edu.br

3 Mestranda do Programa de Pós-Graduação em Ensino (POSENSINO), da Universidade Estadual do Rio Grande do Norte (UERN), Universidade Federal Rural do Semi-Árido (UFERSA) e Instituto Federal de Educação, Ciência e Tecnologia do Rio Grande do Norte (IFRN). Professora da Rede Municipal de Ensino de Mossoró - RN. Professora substituta da Universidade do Estado do Rio Grande do Norte (UERN), Campus Avançado de Patu (CAP). Membro do Grupo de Pesquisa Imagem e Ensino: percepções, métodos e fontes. ORCID: http://orcid.org/0000-0002-1204-9579. E-mail: gdsbento@hotmail.com
} 
Resultados, ainda que parciais, indicam a predominância de uma formação tradicional dos professores de História. Ademais, verificouse também a dicotomia entre a discussão teórica tecida na academia e a prática docente cotidiana, evidenciando um desalinho entre currículo e ensino de História. A partir dessas sistematizações, há indicativos para se repensar a formação inicial dos futuros professores, a fim de formar um profissional para uma cultura de tolerância e respeito à diversidade, possibilitando o desenvolvimento de um saber plural e significativo.

Palavras-chave: Formação de professores de História. Currículo. Ensino. Mulheres.

\section{THE INITIAK TRAINING OF HISTORY OF PROFESSORS OF THE UNIVERSIDADE DO ESTADO DO RIO GRANDE DO NORTE (UERN) FROM THE CURRICULUM: TRACES OF NA ABSENCE ON THE TOPIC 'WOMEN'}

\section{ABSTRACT}

The purpose of this article is to analyze the initial training of the history professors of the Universidade do Estado Rio Grande do Norte (UERN), built from the official curriculum. In the meantime, we specifically discuss the curriculum of the History course and its relationship with teaching, based on the gender / women theme. This is a bibliographical research, comparing the studies of Bittencourt (2011), Fonseca (2003), Nóvoa (2005) and Pinsky (2009), followed by a documental analysis of the 2019.1 curricular structure of the course. Results, even partial, indicate the predominance of a traditional formation of history professors. In addition, there was also a dichotomy between the theoretical discussion woven in academia and the daily teaching practice, showing a mismatch between curriculum and history teaching. From these systematizations, there are indications to rethink the initial formation of future teachers, in order to train a professional for a culture of tolerance and respect for diversity, enabling the development of a plural and meaningful knowledge. 
Keywords: History professors training. Curriculum. Teaching. Women.

\section{LA FORMACIÓN INICIAL DE LOS PROFESORES DE HISTORIA DE LA UNIVERSIDADE DO ESTADO DO RIO GRANDE DO NORTE (UERN) A PARTIR DEL CURRÍCULO: RASGOS DE UNA AUSENCIA SOBRE EL TEMA 'MUJERES'}

\section{RESUMEN}

El presente artículo tiene por finalidad analizar la formación inicial de los profesores de Historia de la Universidad do Estado Rio Grande do Norte (UERN), construida a partir del currículo oficial. Mientras tanto, discutimos, específicamente, el currículo de estudios del curso de Historia y su relación con la enseñanza, basado en el tema mujeres. El presente estudio se presenta como una investigación bibliográfica, basado en los estudios de Bittencourt (2011), Fonseca (2003), Nóvoa (2005) y Pinsky (2009), seguido de un análisis documental de la estructura curricular 2019.1 del curso. Los resultados, aunque parciales, indican el predominio de una formación tradicional de los profesores de Historia. Además, también hubo una dicotomía entre la discusión teórica entretejida en la academia y la práctica docente diaria, evidenciando un desajuste entre el currículo y la enseñanza de Historia. A partir de estas sistematizaciones, hay indicaciones para repensar la formación inicial de los futuros docentes, a fin de capacitar a un profesional para una cultura de tolerancia y respeto a la diversidad, posibilitando el desarrollo de un saber plural y significativo.

Palabras clave: Formación de profesores de Historia. Currículo. Enseñanza. Mujeres. 


\section{INTRODUÇÃO}

É consensual que o cenário enfrentado pela sociedade hoje é complexo, desafiador e demanda do sujeito competências e habilidades plurais. Segundo Habermas (2000) e Buck-Morss (2002), o mundo no qual vivemos está em constante transformação e expansão, marcado por incertezas, provisoriedade e/ou transitoriedade. Um contexto que, sem dúvidas, influencia também o ambiente educativo, dado que o ensinar tornou-se uma atividade complexa, impulsionando os docentes a repensar suas práticas em sala de aula.

A universidade, lócus de construção do conhecimento e dos saberes, competências e habilidades necessárias à formação do sujeito, procura analisar o seu papel na formação do professor que ingressará no mercado de trabalho; da mesma forma, procura atualizar os seus entendimentos acerca da educação, da escola, do aluno e da sociedade (TEIXEIRA, 1998).

Bittencourt (2011) aponta que essa reflexão deve estar presente nos cursos de formação inicial, bem como na formação continuada dos professores, para a efetivação de uma prática pedagógica que responda às demandas das atuais gerações. Outrossim, o desafio que se impõe ao professor de História é a heterogeneidade/pluralidade encontrada em sala de aula, advinda de sujeitos históricos e sociais, portadores de diferentes anseios frente ao mundo contemporâneo.

A formação dos professores do curso de História da Universidade do Estado do Rio Grande do Norte (UERN) é o objeto deste estudo. Destarte, abordaremos debates referentes à temática das mulheres, na formação de professoras/es, por entendermos que a universidade desempenha papel fundamental para a constituição de cidadãos plurais. Cidadãos estes que são alunos no presente, mas no futuros, serão os formadores e contribuirão para que seja consolidado o exercício do respeito ao outro, que lutarão pela consolidação da liberdade de expressão e de escolhas.

Nessa perspectiva, este artigo pretende discutir a relação entre o Ensino de História e a temática das mulheres, no curso de 
Licenciatura em História da UERN. Ao suscitar o debate sobre a temática das mulheres na academia, pretendemos promover um movimento de inclusão, lutando pelo fim das identidades rígidas configuradas ao longo dos anos. Trata-se de lutar por um mundo onde haja igualdade entre o ser mulher ou o ser homem (PINSKY; PEDRO, 2012). Depreende-se, então, que os licenciandos em História podem tornar-se responsáveis pela disseminação de estereótipos e preconceitos, quando seus formadores repetem práticas de abordagem cujas temáticas já estão superadas.

Fonseca (2003) destaca que o processo formativo do educador dá-se ao longo da vida, por meio de vivências socioeducativas. O autor ressalta a importância da formação inicial para a construção da docência por se tratar de "um importante momento de construção da identidade pessoal e profissional do professor, espaço de construção de maneiras de ser e estar na futura profissão" (FONSECA, 2003, p. 60).

Isto posto, observamos que a formação inicial dos professores de História deve se contrapor, por exemplo, às perspectivas sexistas que ainda dominam algumas instituições de ensino superior. Uma questão importante a ser enfatizada é acerca das demandas capazes de orientar a reformulação dos cursos de Licenciatura em História, advindas do meio social em que alunos e professores se inserem. Um dos objetivos da Licenciatura em História é portanto, formar professores/historiadores que estejam capacitados a atuar na produção, problematização e comunicação do conhecimento histórico a partir de seus contextos de vivência e das demandas do seu tempo.

Portanto, este artigo tece suas ponderações em três momentos que se associam simultaneamente: 1) problematizar a formação que vem sendo desenvolvida nas universidades para observar se ela atende as necessidades dos ensinantes e aprendentes na conjuntura atual; 2) refletir sobre a incorporação da temática acerca das mulheres na produção historiográfica; e 3) verificar a partir da grade curricular vigente do curso de História da UERN, 'se' e 'de que' forma a temática acerca das mulheres é contemplada. Quanto à metodologia empregada, faremos uma revisão bibliográfica sobre a 
temática, sequenciado pela análise documental da grade curricular 2019.1 e suas respectivas ementas.

FORMAÇÃO DE PROFESSORES DE HISTÓRIA: primeiras palavras

Me movo como educador, porque, primeiro, me movo como gente.

Paulo Freire

A formação de professores é uma atividade eminentemente humana, inscrita no campo da educação como uma perspectiva teórica, uma temática promissora para as pesquisas e uma prática pedagógica. É, portanto, uma atividade complexa, discutida amplamente em escala mundial sobremaneira na década de 1980, mostrando-se uma área fértil para estudos e pesquisas sob diferentes enfoques. Nesse debate, que não é recente, Gauthier (2006, p. 17) afirma que "[...] embora ensinar seja um ofício exercido em quase todas as partes do mundo, sem interrupção desde a antiguidade, ainda se sabe muito pouco a respeito dos fenômenos que lhe são inerentes". Partindo desse pressuposto, intensificaram-se, nas últimas décadas, discussões a esse respeito, surgindo inúmeras propostas e tendências de formação.

Em sintonia com as diversas fases da História da Educação Brasileira, que preconizavam mudanças estruturais nas formas de ensinar e aprender e influenciadas pelas novas concepções (Escola Nova, o Tecnicismo, o Construtivismo e o Sociointeracionismo), muitas foram as tentativas de mudanças surgidas quanto à formação e profissão docente (MIZUKAMI, 1986). Elas repercutiram em ações voltadas para a formação de professores, de modo que cada uma acaba refletindo uma concepção do papel a ser desempenhado pelo professor em seu exercício profissional.

Situando a discussão acerca da formação do professor e especificamente na área de História, a partir da década de 1980, Fonseca (2003) identifica conflitos no processo de formação inicial, especialmente no tocante à produção acadêmica e ao Ensino de História, na Educação Básica, 
Enquanto nos cursos superiores, os temas eram objeto de várias leituras e interpretações e predominava uma diversificação de abordagens, problemas e fontes, nas escolas de ensino fundamental e médio, de uma maneira geral, as práticas conduziam à transmissão de apenas uma história, uma versão que se impunha como verdade. A formação universitária constituía o espaço da diversificação, do debate, do confronto de fontes e interpretações. A escola, o lugar da transmissão. E o livro didático, na maioria das vezes, a principal senão a única fonte historiográfica utilizada pelos professores (FONSECA, 2003, p. 60-61).

Perguntamo-nos, então, sobre as possíveis origens desse desalinho. Um breve passeio pela História do Ensino de História sugere que as licenciaturas curtas, no contexto da Ditadura Militar no Brasil, descaracterizaram a área de humanidades do currículo escolar, sobretudo quanto aos conteúdos, didática e ofício do professor de História. Graças aos movimentos crescentes de reação e resistência, às pressões políticas e sociais, ao processo de redemocratização do Brasil, à expansão do sistema educacional e às mudanças curriculares para o ensino fundamental, médio e superior, o cenário se reverteu (CERRI, 1997).

Entretanto, ainda se encontra nos cursos de História um currículo pouco inovador, afastado em tematizar questões mais atualizadas e relevantes da sociedade. Contudo, entendemos que currículos são escolhas teóricas e metodológicas, advindas de uma seleção. A impossibilidade de se debruçar sobre a totalidade do acontecido força as escolhas, seleciona os conteúdos e a maneira de tratá-los, baseados em determinados critérios que também são frutos dos contextos. Elucidar se o currículo oferecido na graduação de História prepara adequadamente os futuros professores torna-se o grande desafio das Licenciaturas. Descortinando o debate acerca dos saberes necessários à prática docente, situando o problema na escolha do que se deve ensinar aos que irão ensinar História, Nóvoa (2005, p. 41) adverte,

Mas tem sido difícil instituir programas que, assegurando a necessária preparação científica, não 
descurem a dimensão pedagógica, nem a relação à prática e à cultura profissional docente. Sobrepor as disciplinas de base às ciências da educação e às práticas de ensino não resolvem qualquer problema. Mas são muitos os interesses que dificultam a necessária reforma. E aí não será a formação contínua a colmatar as deficiências da formação inicial. O século XXI abre com uma grave indecisão nessa matéria. (NÓVOA, 2005, p. 41).

Nóvoa (2005) discorre sobre a falta de articulação entre currículo e prática docente, o que influencia diretamente na dinâmica do ensino-aprendizagem. O professor necessita de uma formação que contemple as necessidades cotidianas no ambiente escolar. Além da competência técnica, esse profissional precisa de outras habilidades para atingir seu objetivo em sala de aula. Estudos de Karnal (2008) têm demonstrado a importância de o docente dominar e abordar coerentemente $\mathrm{o}$ processo histórico, observando permanências e mudanças que, na vida social, ressoam do passado até nossos dias. Na seleção de conteúdos, o professor é convidado a primar por temas congruentes com os objetivos da disciplina, com as competências e habilidades que deverão ser desenvolvidas pelo aluno ao longo de sua formação considerando as singularidades de cada um.

Surgem então questões a serem pensadas: o que se deve ensinar na disciplina de História? Qual conteúdos tornam a disciplina atraente para os alunos? Quais conteúdos garantem uma formação adequada? Que metodologia é capaz de produzir um diálogo entre o que aconteceu e que foi produzido historicamente com o que é trabalhado e contextualizado em sala de aula?

Em vista da superação do ensino tradicional de História e na busca do ideal, configura-se um imperativo para a disciplina formar - aluno-cidadão dotado de consciência crítica, por vezes denominado de "novo" homem para atuar em uma nova sociedade (FONSECA, 2003).

Vale ressaltar que, no encaminhamento dos novos procedimentos e suas justificativas, convenciona-se que o ensino deveria centrar-se em 
[...] discussões temáticas, relacionadas com o cotidiano do aluno, seu trabalho e sua historicidade. $\mathrm{O}$ objetivo era recuperar $\mathrm{O}$ aluno como sujeito produtor da História e não como um mero expectador de uma história já determinada, produzida pelos heroicos personagens dos livros didáticos. (SCHIMDT; CAINELLI, 2004, p. 15).

É possível perceber que nesses embates e discussões em torno de proposições sobre o ensino de História, o professor ocupa papel ímpar. Ele é responsável por gerir o processo de construção de saberes, tendo como desafio duas grandes metas: cumprir um currículo extenso e formar sujeitos críticos e autônomos; estabelecer uma articulação entre o conteúdo formal e os saberes trazidos por cada aluno.

Nenhuma metodologia ou técnica de ensino acontece de maneira exitosa se o professor não se lançar como mediador entre o conhecimento historicamente acumulado e o aluno (BITTENCOURT, 2011).

Nessa direção, o professor de História pode estimular o aluno a aprender a se movimentar no tempo, a conseguir situar-se na história das sociedades para compreender a sua. Só assim estará o docente atuando como um mobilizador da inteligência coletiva (SILVA, 2001), ajudando a criar e recriar saberes, contribuindo para o exercício da cidadania e, como consequência, instruir os alunos para se construir uma sociedade mais justa, igual, democrática, solidária e empática.

No bojo dessa articulação, está o currículo que, por conseguinte, vai pautar os conteúdos e práticas em sala de aula. Segundo Thiesen (2013), a seleção de conteúdos deve ser baseada nas atuais demandas sociais. Desta feita, é fundamental que todos os aspectos sociais povoadores dos espaços sociais transformem-se em temas de debate para a comunidade escolar. Incluir a temática 'mulher' como categoria histórica digna de atenção nos processos formativos promove, por exemplo, a redução da desigualdade de gênero e fomenta nas mulheres a consciência de si e de seus direitos e deveres. Os Parâmetros Curriculares Nacionais (PCNs) do ensino fundamental, publicados em 1997, postulam, nos temas transversais, 
a discussão das questões de gênero no ambiente escolar. Se a prática pedagógica deve seguir as orientações legais, os cursos de formação inicial não poderiam excluí-las em seus processos formativos. A este respeito, Pinsky e Pedro (2012) entendem que a escola é um espaço para o debate de gêneros e o professor deve ter condições de mobilizar tais discussões, a fim de desestabilizar o "senso comum" e propor novas formas de pensar e "ver" mundo, estimulando uma cultura de respeito e tolerância entre os sujeitos.

MULHERES: da sombra às produtoras de história

Cronologicamente, foi o movimento feminista que, nos anos 1960, lançou as bases para a criação da História das Mulheres, antecedendo os historiadores. É imperativo realçar que o marco da emergência da História das Mulheres, no Brasil, nasce no interior das reivindicações de direitos trabalhistas das operárias, em 1970. Coincide também que é justamente neste período que a História passa a sofrer profundas mudanças, abandonando os interesses exclusivos dos temas políticos para incorporar outro que abrangiam desde o cotidiano até a vida no interior da família, passando pelos valores, crenças e hábitos que marcavam a classe trabalhadora (PERROT, 1992).

Inquestionavelmente, as décadas de 1970 e 1980 foram de grande valia para a incorporação da temática 'mulheres' na produção historiográfica porque colocavam em discussão a visão monolítica do "Homem Universal." Conforme Pinsky (2009, p. 2),

[...] vários historiadores, após denunciar a exclusão das mulheres nos trabalhos de História feitos até então, procuraram torná-las visíveis na chamada História Geral. Essa preocupação foi especialmente marcante nos primeiros momentos de desenvolvimento da História das Mulheres. Para alguns críticos, entretanto, isso não foi suficiente por não afetar profundamente a historiografia tradicional, com seus recortes temáticos, periodizações, fontes e "fatos históricos" já bem delimitados. 
Ainda segundo a autora, as novas abordagens da História chegavam também às "outras histórias", ou seja, às temáticas tidas como marginais ou secundárias. Nesta esteira, as mulheres, até então silenciadas, passavam a ser vistas também como cidadãs da história e objeto de estudo. Este novo olhar sobre a temática mulher caracterizava, per si, um grande avanço, mas não rompia totalmente com a invisibilidade a que elas estavam sujeitas, como objeto de investigação. Por isso, como Pinsky (2009, p. 2) evidencia

[...] não basta acrescentar as mulheres aos livros de
História [...], é preciso repensar o próprio saber
histórico e privilegiar abordagens analíticas.
Atendendo ao apelo, vários historiadores
procuraram explicar o desenrolar do processo
histórico oferecendo novas narrativas,
apresentando novas causas e demonstrando
consequências antes ignoradas (PINSKY, 2009, p. 2).

A crescente presença das mulheres em diferentes espaços de trabalho e da política, inclusive de cargos de liderança, o número alarmante de casos de violência contra elas, as novas abordagens sobre o papel da mulher na casa, na rua, em ambientes privados e públicos etc, instigaram pesquisadores das mais variadas áreas da academia a refletir, discutir e fazer pensar sobre o lugar das mulheres na História. Ainda que a História constantemente revise suas percepções acerca de um passado, reconstruindo narrativas, cabe ao professor de História ancorar práticas pedagógicas que promovam olhar o passado em uma perspectiva plural, diversificada e contextualizada (PINSKY, 2009).

\section{A GRADE CURRICULAR DO CURSO DE HISTÓRIA DA UERN E A} TEMÁTICA DA MULHER: traços de uma ausência

O Curso de Licenciatura em História, na UERN, foi legalmente constituído em 16 de novembro de 1966, através da Resolução no 065/65. A instalação ocorreu em 13 de dezembro de 1966, recebendo a primeira turma em 1967. O reconhecimento junto ao Ministério da Educação com a estrutura departamental deu-se pelo decreto-Lei 
79.017, de 23 de dezembro de 1976. O curso postulava o papel de oportunizar a formação de profissionais voltados ao Ensino Básico público que, por sua vez, representava $6,7 \%$ das vagas oferecidas nos cursos de graduação da UERN, sendo distribuídas nas cidades de Mossoró e Assu.

Atualmente, o curso de História está assim planificado:

Quadro 1 - Estrutura curricular do curso de História da UERN

\begin{tabular}{|l|l|}
\hline Curso & $(100620-0)$ História - Licenciatura \\
\hline Matriz curricular & $\begin{array}{l}\text { 2019.1 (válida para ingressantes a partir de } \\
\text { 2019.1) }\end{array}$ \\
\hline Campus/Cidade & Campus Central - Mossoró \\
\hline Faculdade & Faculdade de Filosofia e Ciências Sociais - FAFIC \\
\hline Disc. Obrigatórias & 2745 horas \\
\hline Disc. Optativas & 600 horas \\
\hline Ativ. Complementares & 210 horas \\
\hline Carga horária total & 3555 horas \\
\hline Semestres & 9 (entre 4,5 e 7 anos - máximo) \\
\hline
\end{tabular}

Fonte: Quadro elaborado pelos autores com dados extraídos da UERN - Curso de História (2019).

Em relação ao quantitativo de egressos, a instituição tem apresentado anualmente o valor aproximado de quarenta licenciados em História. No que tange aos objetivos do curso, de modo geral, o PPC (Projeto Pedagógico do Curso) explicita que os profissionais (professores de História) devem atuar na construção do pensamento crítico de seus alunos, para que estes possam ser atuantes nos processos políticos e sociais das suas respectivas localidades e na sociedade em geral, considerando o uso competente e reflexivo das Tecnologias de Informação e Comunicação (TIC). Somados ao objetivo principal, deparamo-nos com dois objetivos específicos que consideramos extremamente relevantes para nossa pesquisa. São eles:

a) Atentar para o reconhecimento de experiências de sujeitos individuais e coletivos em diferentes temporalidades e espacialidades, a fim de formar o profissional para uma cultura de tolerância e respeito à diversidade; 
b) Possibilitar uma formação global, dialogando com outras áreas de saber e capacitando o aluno para uma intervenção criativa e dotada de intencionalidade diante das questões complexas que se colocam na contemporaneidade (UERN, 2019).

Assentados nas informações citadas acima, notamos que o curso de História da UERN possui uma matriz curricular que responde (e muito!) aos desafios que hoje se impõem ao professor de História. Conquanto, ao continuarmos nosso estudo sobre o referido documento, especificamente no tocante à disciplina/atividade, não identificamos dentre as obrigatórias, nenhuma que contemplasse a discussão 'mulheres' em suas ementas. Por conseguinte, partimos, então, para outros componentes (disciplinas optativas) e encontramos as descritas no Quadro 2.

Quadro 2 - Curso de História - Outros Componentes

\begin{tabular}{|c|c|c|c|c|c|}
\hline Código & Disciplina & Ementa & $\mathrm{CH}$ & Aplicação & Situação \\
\hline 0301064-1 & $\begin{array}{l}\text { Educação } \\
\text { para } \\
\text { Diversidade }\end{array}$ & $\begin{array}{l}\text { Política nacional de } \\
\text { atenção educacional } \\
\text { às pessoas com } \\
\text { necessidades } \\
\text { especiais, minorias e } \\
\text { demais casos de } \\
\text { negação de direitos na } \\
\text { sociedade. A } \\
\text { formação de } \\
\text { professores numa } \\
\text { perspectiva de } \\
\text { atendimento à } \\
\text { diversidade Prática } \\
\text { Pedagógica e acesso } \\
\text { ao conhecimento } \\
\text { numa perspectiva do } \\
\text { princípio de Educação } \\
\text { para Todos. }\end{array}$ & 60 & Teórica & Optativa \\
\hline 0701105-1 & $\begin{array}{c}\text { Ética e } \\
\text { Cidadania }\end{array}$ & $\begin{array}{l}\text { Ética } \\
\text { responsabilidade. } \\
\text { Ética e moral. Noções } \\
\text { de cidadania. } \\
\text { Cidadania e esfera }\end{array}$ & 60 & Teórica & Optativa \\
\hline
\end{tabular}




\begin{tabular}{|l|l|l|l|l|}
\hline & $\begin{array}{l}\text { pública. Cidadania, } \\
\text { direitos } \\
\text { sociais e participação } \\
\text { política. }\end{array}$ & & & \\
\hline
\end{tabular}

Fonte: Quadro elaborado pelos autores com dados extraídos da UERN - Curso de História (2019).

O Quadro 2 mostra que somente a disciplina Educação para Diversidade, na matriz curricular vigente, é responsável por discutir temas, trazer teóricos e estudos relativos ao direito das pessoas com deficiência, dos que ficam à margem na sociedade. Verificamos que a disciplina não dá conta de discutir temas tão caros à contemporaneidade, entre eles, como a questão das mulheres, contrariando, assim, o princípio da educação para todos, que deve estar presente nos cursos de graduação. Identificamos também que esse componente curricular é ofertado como disciplina optativa/eletiva, logo, sem obrigatoriedade, ficando a cargo do licendiando decidir cursá-lo ou não.

Ainda analisando o Quadro 2, percebemos que a disciplina Ética e Cidadania, também optativa, mesmo tratando de temáticas referentes à cidadania e direitos sociais, não apresenta em seu arcabouço um eixo norteador para temática acerca das Mulheres. Logo, há um hiato, uma falta que, se preenchido, muito enriqueceria a grade curricular do curso de História.

A ausência de uma disciplina específica sobre a temática Mulher não é exclusiva da UERN. A lacuna também ocorre na maioria dos cursos de História das universidades públicas e, majoritariamente, em instituições privadas.

Ainda acerca das disciplinas presentes no Quadro 2, vemos que versam sobre os direitos fundamentais do cidadão, e queremos evidenciar nesse texto o direito à educação, como preconizam o art. $6^{\circ}$ da Constituição da República Federativa do Brasil (CRFB/88), e a Lei n 9.394/96 - Lei de Diretrizes e Bases da Educação Nacional (LDB). Logo, provoca estranhamento que os currículos dos futuros professores estejam distantes das diretrizes legais, as quais asseguram que a educação é o caminho para a construção do respeito à diversidade e igualdade. Além disso, o Brasil participa de diversos pactos e convenções internacionais que buscam promover a 
igualdade de gênero e a redução da violência contra a mulher, tais como: como a Convenção para Eliminação de Todas as Formas de Discriminação contra a Mulher (1979), a Conferência Mundial para a Revisão e Avaliação das Realizações da Década das Nações Unidas para a Mulher: Igualdade, Desenvolvimento e Paz (1985), a Conferência Interoamericana para Prevenir, Punir e Erradicar a Violência Contra a Mulher, a Quarta Conferência Nacional sobre as Mulheres (1995), as quais foram desenvolvidas pela Organização das Nações Unidas (ONU). Além disso, esse organismo criou, em 2010, o ONU Mulheres, mecanismo importante para a elaboração de políticas públicas para a promoção da equidade de gênero. Dada a significativa dimensão dessa problemática, é fundamental que as propostas curriculares de formação de professores possam contemplar discussões sobre a questão do gênero.

O silenciamento existente quanto à perspectiva de tematizar as mulheres na academia reverbera diretamente na sala de aula. De modo específico, abordamos a questão da mulher na formação de professoras/es como uma forma de chamar a atenção para futuras discussões a respeito da reformulação do currículo da disciplina de História. Decerto, essa reflexão precisa ampliar o foco e não recobrir somente o ensino da disciplina de História; no entanto, trata-se de uma temática relevante na configuração do objeto de ensino da História e nos desdobramentos que dele derivam. Nas palavras de Miranda (2013, p. 106), "[...] o debate sobre as dimensões que envolvem a aprendizagem histórica precisa levar em conta a diversidade existente entre grupos e sujeitos".

A força motriz para essa discussão reside na percepção daquilo que muitos pesquisadores já diagnosticaram, como salienta, por exemplo, Perrot (1992, p. 185), "Da História, muitas vezes a mulher é excluída". Outo ponto a ser ressaltado é que, quando a disciplina que, de algum modo, toca na acerca da temática Mulheres é oferecida, apresenta-se como disciplina eletiva, opcional. Ousamos dizer que, no interior dessa polêmica, está a formação inicial dos futuros professores, alicerçadas em fundamentos tradicionais, reflexo de uma História contada nos moldes do patriarcalismo, onde a História sempre foi feita por homens e para homens, reforçando a invisibilidade feminina (PERROT, 1992). Essa invisibilidade, portanto, 
faz emergir um imaginário coletivo de que as mulheres sempre estiveram sob a sombra masculina e não foram inventivas o suficiente para fazer girar as engrenagens sociais e políticas.

\section{CONSIDERAÇÕES FINAIS}

Os apanhados apresentados neste artigo evidenciam que, no campo da formação inicial dos professores de História da UERN, sobretudo no aspecto curricular, predominam, em alguns casos, ainda conteúdos costumeiros, o que repercute em uma dicotomia entre a discussão teórica tecida na academia com a prática docente cotidiana. Nesse contexto, percebemos um desalinho entre o currículo e o ensino de História, quando se trata da ausência da temática das Mulheres em sua grade curricular. Isso porque os currículos dos cursos de Licenciatura em História devem contemplar temáticas já abordadas pela Nova História, tão preocupada com os objetos atuais e com as diversas (re)configurações dos currículos.

No que concerne especificamente ao curso de História da UERN, a matriz curricular 2019.1 analisada nesse artigo, constata-se que o currículo desenvolvido na graduação segue pautado na construção de um saber e/ou formação tradicional. Assim, a temática sobre as Mulheres não é abordada e a disciplina é oferecida na modalidade opcional. Inferimos que as discussões sobre Mulheres, bem como as que abordam as questões das minorias, não são contempladas com uma carga horária satisfatória e transversal no decorrer do curso.

Observamos que a ausência da temática em um curso de Licenciatura em História repercutirá em outras dimensões: se o professor não obter uma formação adequada para abordar o tema das mulheres, consequentemente e dificilmente abordará na a sala de aula da educação básica. Como o professor poderá formar seus alunos-cidadãos para uma cultura do respeito à mulher se em sua própria formação isso não se efetivou?

Entendemos que essas e outras inquietações são oriundas de práticas formativas que necessitam de atualizações, pois um currículo pensado sem conexão com o contexto de quem irá aprender obstrui a reflexão a respeito da complexidade e a totalidade do ser humano. 
Além disso, é importante pensar numa formação docente que possa contemplar a diversidade de concepções em relação ao papel feminino ao longo da História. De acordo com Perrot (2005, p. 29), "[...] a dificuldade da história das mulheres deve-se inicialmente ao apagamento dos seus traços, tanto públicos quanto privados".

Frisamos que uma licenciatura em História deve propiciar aos discentes uma formação ampla, que Ihes permita dialogar com a sociedade, com as diretrizes normativas do ensino, promovendo modificações no meio a que pertencem, comprometimento com valores democráticos e sociais fundamentais para a construção de uma sociedade mais justa e igual. De igual modo, um curso de Licenciatura em História precisa refletir sobre a educação inclusiva, estimulando o respeito às diferenças, reconhecendo e valorizando a diversidade étnico-racial, sexual, religiosa, de gênero e de faixa geracional. Dessa forma, o licenciado em História estará capacitado para atuar tanto no âmbito escolar, como em práticas não-escolares de ensino, quanto para investigar e refletir sobre temáticas atuais emergentes. Também será capaz de desenvolver a pesquisa e a produção do conhecimento histórico não só no âmbito da produção acadêmica propriamente dita, como também em instituições de pesquisa, de preservação documental, cultural, assim como nas redes pública e privada de ensino. Trabalhará, portanto, com todas as dimensões da História, dominando conhecimentos específicos da sua área, bem como com as metodologias e técnicas essenciais à produção e divulgação do ensino e do conhecimento histórico.

Sem a pretensão de esgotar esse debate que julgamos absolutamente efervescente no pensamento educacional e curricular, ousamos salientar essa falta, esse vazio que pode ser resolvido. E o fazemos por acreditar que toda pesquisa incide sobre o Ensino, que a pesquisa existe justamente para interferir, modificar, transformar e engrandecer o exercício do Ensino em sala de aula. Além do mais, pesquisa e ensino não estão apartados das questões sociopolíticas, culturais e econômicas que envolvem a interrelação entre diversas competências.

Cabe não somente à UERN, mas a tantas outras, o papel de formar docentes comprometidos com uma inserção abrangente e que inclua a temática sobre as Mulheres. Por meio dos cursos de 
formação de professores na academia, será possível transformar, revisar e contemporaneizar as temáticas contempladas em um curso universitário, sobremaneira aqueles que tratam do humano, das pessoas, dos sujeitos e indivíduos que fazem da História não só uma disciplina, mas uma oportunidade de revisões, de recomeços. Para isto, as instituições de Ensino Superior são convidadas a rever certos conceitos e regras firmemente estabelecidas (PINSKY, 2009).

A título de sugestão e de continuidade da reflexão, para além do exercício da docência no Ensino Fundamental (séries finais) e Médio, elencamos algumas propostas de pesquisas que os licenciados em História podem fazer uso: a) desenvolver projetos de pesquisa que tematizem as contribuições das Mulheres no decurso do tempo; b) fortalecer projetos sociais inclusivos e educativos com vistas à preservação da identidade e formação cidadã da Mulher sob uma ótica multicultural.

Por fim, concluímos que questionar o ensino da História oficial, contada e escrita a partir de um único ponto de vista é uma tarefa premente para os atuais cursos de Licencitura em História, já que visam preparar aqueles que no futuro ensinarão acerca do que estamos vivenciados no momento presente. Nessa perspectiva, cabe mencionar um trecho do samba-enredo da escola de samba Estação Primeira de Mangueira, no carnaval de 2019, quando diz: "Brasil, chegou a vez de ouvir as Marias, Mahins, Marielles, Malês".

\section{REFERÊNCIAS}

BITTENCOURT, Circe Maria Fernandes. Ensino de história:

fundamentos e métodos. 4. ed. São Paulo: Cortez 2011. (Coleção Docência em Formação. Série Ensino Fundamental).

BRASIL. Ministério da Educação (MEC). Secretaria de Educação Fundamental (SEF). Parâmetros Curriculares Nacionais:

apresentação dos temas transversais, ética. Brasília, DF: MEC/SEF, 1997.

BRASIL. BRASIL. Lei n 9.394, de 20 de dezembro de 1996.

Estabelece as diretrizes e bases da educação nacional. Diário Oficial da União, Brasília, DF, 23 dez. 1996. Disponível em: 
http://www.planalto.gov.br/ccivil_03/leis/19394.htm. Acesso em: 27 nov. 2018.

BRASIL. Constituição da República Federativa do Brasil de 1988. Brasília, 5 de outubro de 1988. Disponível em: http://www.planalto.gov.br/ccivil_03/constituicao/constituicaocompil ado.htm. Acesso em: 27 nov. 2018.

BUCK-MORSS, Susan. Dialética do olhar: Walter Benjamin e o projeto das passagens. Belo Horizonte: Ed. UFMG; Chapecó: Ed. Universitária Argos, 2002.

CERRI, Luiz Fernando. As concepções de História e os cursos de Licenciaturas. In: Revista de História Regional. Departamento de História da UEPG. v. 2, n. 2, p. 137-152, Inverno de 1997.

FONSECA, Selva Guimarães. Didática e prática de Ensino de História: experiências, reflexões e aprendizados. 2 ed. Campinas: Papirus, 2003.

GAUTHIER, Clermont. Por uma teoria da pedagogia: pesquisas contemporâneas sobre o saber docente. Trad. Francisco Pereira: ljuí. 2ed: UNIJUI, 2006 (coleção fronteiras da educação).

HABERMAS, Jürgen. A consciência de tempo da modernidade e sua necessidade de autocertificação. In: HABERMAS, Jürgen. $\mathbf{O}$ discurso filosófico da modernidade. São Paulo, Martins Fontes, 2000.

KARNAL, Leandro. História na sala de aula: conceitos e propostas. São Paulo: Contexto, 2008.

MIRANDA, A. R. Reflexões sobre mulheres, gênero e aprendizagem histórica, Historiae, Rio Grande, v.4, .2, p. 103-114, 2013. Disponível em: https://periodicos.furg.br/hist/article/view/3680. Acesso em: 12 maio de 2020.

MIZUKAMI, M.G.N. Ensino: as abordagens do processo. São Paulo: EPU, 1986.

NÓVOA, Antonio. Evidentemente. Histórias da Educação. Porto: Asa Editores, 2005. 
PERROT, Michelle. As mulheres ou os silêncios da história. Trad. Viviane Ribeiro. Bauru: EDUSC, 2005.

PERROT, Michelle. Os excluídos da História: operários, mulheres e prisioneiros. 2. ed. Rio de Janeiro: Paz e Terra, 1992.

PINSKI, Carla, Bassanezi. Estudo de Gênero e Histórial Social. Rev. Estud. Fem. v.17, n. 1, Florianópolis, jan. 2009. Disponível em:

http://www.scielo.br/cgi-bin/wxis.exe/iah/. Acesso em 14 nov. 2019. PINSKI, Carla, Bassanezi; PEDRO, Joana Maria (orgs). Nova História das Mulheres. São Paulo: Contexto, 2012.

SAMBA-ENREDO MANGUEIRA. História para ninar gente grande. 2019. Disponível em: https://www.letras.mus.br/sambas/mangueira2019/. Acesso em: 15 fev. 2020.

SCHMIDT, Maria Auxiliadora; CAINELLI, Marlene. Ensinar História. São Paulo: Scipione, 2004.

SILVA, Marco. Sala de aula interativa. 2. ed. Rio de Janeiro: Quartet, 2001.

TEIXEIRA, A. Educação e universidade. Rio de Janeiro: Editora UFRJ, 1998.

THIESEN, Juares da Silva. Currículo Interdisciplinar: contradições, limites e Possibilidades. Florianópolis, Perspectiva, v. 31, n. 2, 591614, maio/ago. 2013.

UERN. Curso de História. 2019. Disponível em:

http://fafic.uern.br/historia/default.asp?item=historia-apresentacao. Acesso em: 03 de maio de 2019.

Submetido em: Maio/2020.

Aceito em: Dezembro/2020. 